\title{
Correction to: Acute Visual Loss
}

\author{
Jane H. Lock, Cédric Lamirel, Nancy J. Newman, \\ and Valérie Biousse
}

\section{Correction to: Chapter 5 in: K. L. Roos (ed.), Emergency Neurology, https://doi.org/10.1007/978-3-030-75778-6_5}

Figure 5.10 had an error in the published version of the book, and the term Pseudopapilledema (in the middle grey box) has now been corrected to Papilledema. The updated figure is provided below.

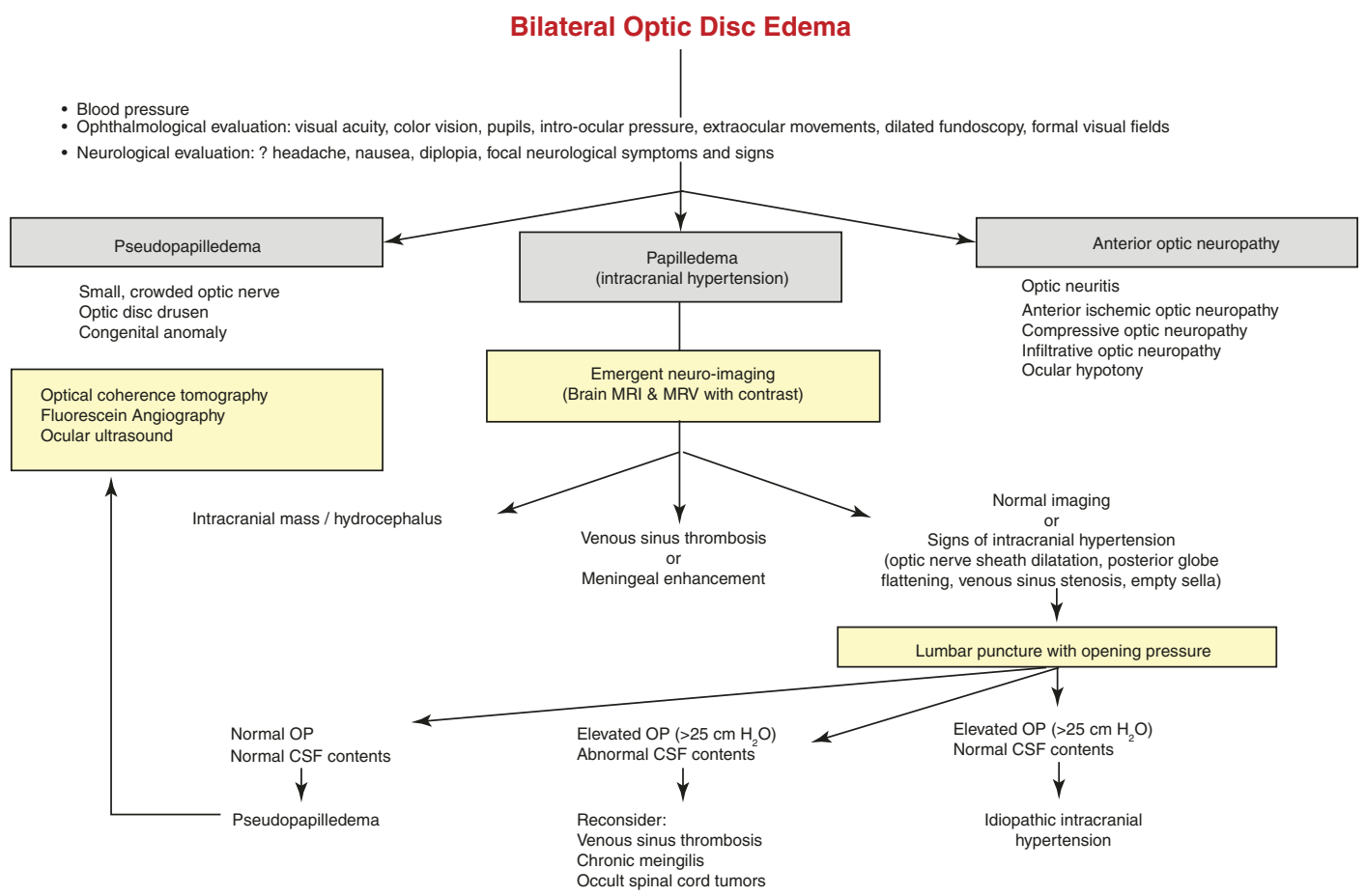

Fig. 5.10 Flowchart detailing the diagnosis of disc edema

The updated version of this chapter can be found at https://doi.org/10.1007/978-3-030-75778-6_5 